\title{
Unusual cause for pacemaker threshold elevation
}

\author{
Osman Can Yontar ${ }^{1}$, Erhan Tenekecioglu' ${ }^{1}$, Kemal Karaagac ${ }^{1}$, Ahmet Tutuncu ${ }^{1}$ \\ ${ }^{1}$ Department of Cardiology, Bursa Postdoctorate Training and Research Hospital
}

\section{A B S T R A C T}

Pacing threshold is an important entity which should be tested during pacemaker follow up. Abnormal elevation of pacing threshold would end up with early exhaustion of pacemaker battery. In this report, we described a patient with an unusual cause for threshold elevation. Learning objective: Pacemaker follow-up has its own routines. Telecardiogram is one of them, however it is mostly underrated nowadays. Our objective is to teach value of this quick and inexpensive test for pacemaker patients.

Access this article online

Website:

http://nepjol.info/index.php/AJMS

Key words: Diaphragma, Pacemaker, Threshold

\section{CASE REPORT}

A 75-year-old female patient admitted to our pacemaker outpatient clinic for regular control. She had complaint of abdominal distension and dyspneoa especially when she lay back at night. Her VDD pacemaker (Vitatron Saphir 3 VDD) was first implanted nine years ago and she underwent battery replacement (Medtronic Enpulse E2VDD01)2 years ago. According to the records, lead amplitude was $2.5 \mathrm{mV}$ and pacing threshold was $0.9 \mathrm{mV}$ and impedance was $800 \mathrm{ohms}$ at that time, so operator left the lead in current place. Patient's pacemaker interrogation showed end of life alert (less than one month). This finding was unexpected for such a short period after implantation. A threshold test was applied and result was $2.7 \mathrm{mV}$. Current pacing amplitude was $2.5 \mathrm{mV}$. Patient's prior interrogation results were in normal range, lead impedance was $740 \mathrm{ohm}$, pacing threshold was $1.1 \mathrm{mV}$. Current lead impedance was 1980 ohms. Surface electrocardiogram revealed capture failure (Figure 1A). A chest plain film demonstrated a partial white-out of left lung without extrapulmonary air (Figure 1B). After surgery consultation, surgical repair of para-esophageal hernia was recommended. ${ }^{1}$ Patient rejected surgical therapy. Later, battery was replaced and a new lead implanted to a location with better threshold and impedance values (Figure 2).

\section{DISCUSSION}

Pacemaker threshold elevation is generally related with extensive myocardial fibrosis (mainly due to

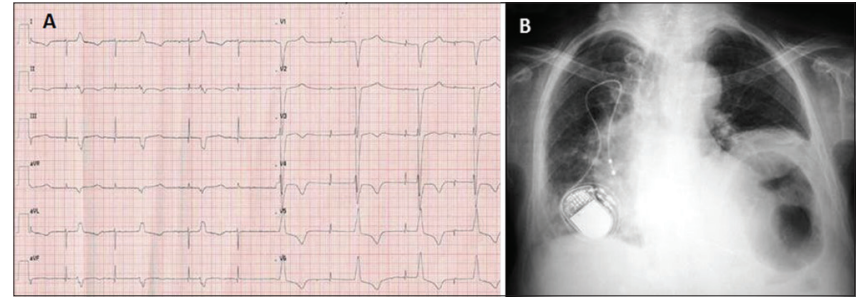

Figure 1: (A) Patient's surface electrocardiogram. Pacing spikes are not related with QRS complex, typical for loss of capture. (B) Patient's anteroposterior telecardiogram. Notice the colon segments filling thorax

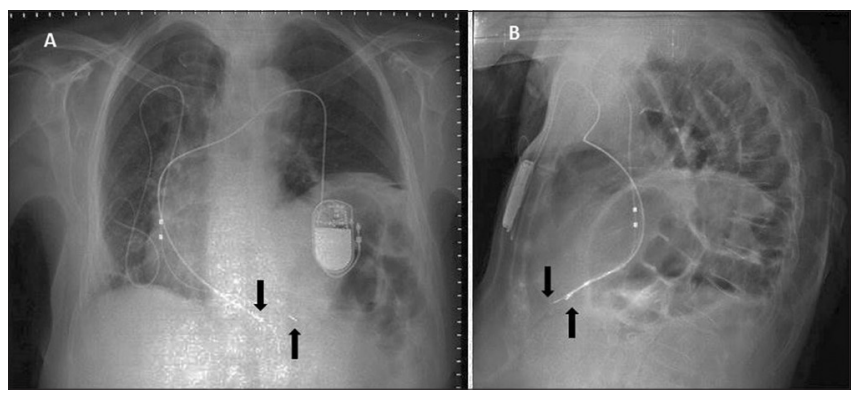

Figure 2: After reimplantation telecardiograms. (A) Anteroposterior and $(B)$ lateral views, arrows show true positioning of the new pacing electrode

infarction) and lead dislodgement. ${ }^{2}$ In our case, it seems that herniated segment provided an external push to the ventricle and caused displacement and insufficient contact of the lead tip. True apical position is easily noticed on the chest $\mathrm{x}$-ray after the procedure (Figure 2). 


\section{CONCLUSION}

Telecardiogram and surface electrocardiogram are "sine qua non" for pacemaker patients" follow-up. These two tests are inexpensive and provide valuable information for clinician without consuming time. Some rare aetiology behind pacemaker problems could be enlightened by these two feasible tests (3). A plain telecardiogram may reveal the underlying problem, which is para-esophageal hernia in this case.

\section{REFERENCES}

1. Abbara $\mathrm{S}$, Kalan $\mathrm{MH}$ and Lewicki AM. Intrathoracic stomach revisited. Am J Rad 2003; 181:403-414.

2. Schoenfeld MH and Markowitz HT. Device follow-up in the age of automaticity. Pacing Clin Electrophysiol 2000;23(5):803-806.

3. Belvin D, Hirschl D, Jain VR, Godelman A, Stein MW, Gross JN, et al. Chest radiographs are valuable in demonstrating clinically significant pacemaker complications that require reoperation. Can Assoc Radiol J 2011; 62(4):288-295.

Authors Contribution:

OCY - Writing, finder of case patient; ET - Writing, English translation; KK - Supervision, correction; AT - Finder of case, English translation.

Source of Support: Nil, Conflict of Interest: None declared. 